\title{
BMJ Open Awareness and enforcement of guidelines for publishing industry-sponsored medical research among publication professionals: the Global Publication Survey
}

\author{
Elizabeth Wager, ${ }^{1}$ Karen Woolley, ${ }^{2,3,4}$ Viv Adshead,${ }^{5}$ Angela Cairns, ${ }^{5}$ Josh Fullam, ${ }^{6}$ \\ John Gonzalez, ${ }^{7}$ Tom Grant, ${ }^{7, *}$ Stephanie Tortell ${ }^{8, *}$
}

To cite: Wager E, Woolley K, Adshead V, et al. Awareness and enforcement

of guidelines for publishing industry-sponsored medical research among publication professionals: the Global Publication Survey. BMJ Open 2014;4:e004780. doi:10.1136/bmjopen-2013004780

- Prepublication history for this paper is available online. To view these files please visit the journal online (http://dx.doi.org/10.1136/ bmjopen-2013-004780).

${ }^{*} \mathrm{TG}$ is now based at Complete HealthVizion, Macclesfield, Cheshire, UK and ST is now based at KnowledgePoint 360 Group, Macclesfield, Cheshire, UK.

Received 31 December 2013 Revised 31 March 2014 Accepted 1 April 2014

CrossMark

For numbered affiliations see end of article.

Correspondence to Dr Elizabeth Wager; liz@sideview.demon.co.uk

\section{ABSTRACT}

Objective: To gather information about current practices and implementation of publication guidelines among publication professionals working in or for the pharmaceutical industry.

Design/setting: Web-based survey publicised via email and social media to members of the International Society for Medical Publication Professionals (ISMPP) and other organisations from November 2012 to February 2013.

Participants: 469 individuals involved in publishing industry-sponsored research in peer-reviewed journals, mainly working in pharmaceutical or device companies ('industry', $n=144$ ), communication agencies ('agency', $n=238$ ), contract research organisations (CRO, $n=15$ ) or as freelancers $(n=34)$. Most respondents $(78 \%)$ had worked on medical publications for $\geq 5$ years and $62 \%$ had a PhD/MD.

Results: Over $90 \%$ of industry, agency and CRO respondents routinely refer to Good Publication Practice (GPP2) and the International Committee of Medical Journal Editors' Uniform Requirements. Most respondents (78\% industry, $79 \%$ agency) received mandatory training on ethical publication practices. Over $90 \%$ of respondents' companies had publication guidelines or policies and required medical writing support to be acknowledged in publications ( $96 \%$ industry, $99 \%$ agency). Many industry respondents used publication management tools to monitor compliance with company guidelines and about half $(46 \%)$ stated that their company had formal publication audits. Fewer agencies audited adherence to guidelines but $20 \%$ of agency respondents reported audits of employees and $6 \%$ audits of freelancers. Of concern, $37 \%$ of agency respondents reported requests from authors or sponsors that they believed were unethical, although $93 \%$ of these requests were withdrawn after respondents explained the need for compliance with guidelines. Most respondents' departments (63\% industry, $58 \%$ agency, $60 \%$ CRO) had been involved in publishing studies with negative or inconclusive results. Conclusions: Within this sample, most publication professionals working in or for industry were aware of,

\section{Strengths and limitations of this study}

- Large-scale international survey of publication professionals $(\mathrm{n}=469)$.

- Focused on awareness and implementation of guidelines relating to responsible publication practice, providing insight into current industry practices.

- Included publication professionals (eg, writers, planners and managers) working in pharmaceutical and medical device companies, medical communication agencies, contract research organisations or as freelancers.

- Survey allowed anonymous responses.

- Limited response from freelancers $(n=34)$, journal editors, publishers and academics $(n=38)$.

- Self-selection bias may mean that respondents were not representative of the total population if those with a particular interest in, or concerns about, ethical publication practices were more likely to complete the survey than those with less knowledge, interest or concerns.

- Methods used for publicising the survey (via websites, social media, etc) meant that it was impossible to calculate a precise response rate.

and applying, major publication guidelines. However, the survey also identified specific areas where education and promotion of guidelines are needed to ensure ethical publication practices.

\section{INTRODUCTION}

Misleading, inaccurate or incomplete reporting of clinical trial findings can have serious consequences, since doctors and policymakers rely on publications when developing treatment guidelines and making decisions affecting patients. The involvement of 
medical writers and other publication professionals, such as planners and managers, in developing peerreviewed publications reporting clinical trials has been criticised by some, ${ }^{1}{ }^{2}$ but defended by others. ${ }^{3} 4$ Similarly, while some studies have shown that publications funded by pharmaceutical companies are of equal or higher quality than publications from academia, ${ }^{5-7}$ others have shown that they are more likely to be biased. ${ }^{8}$ Concern about irresponsible publication practices, from within and outside the industry, has led to the creation and evolution of several guidelines. ${ }^{4}{ }^{10-13}$ These guidelines seek to establish responsible publication practices, increase transparency and prevent bias and commercial influence in reporting medical research. While many have welcomed such guidelines, critics of the pharmaceutical industry remain unconvinced, for example, commenting "Publicly, they insist that everything has changed... But my concern is this. Having seen so many codes openly ignored and broken, it's hard to take any set of voluntary ideals seriously."14 Given this concern about whether voluntary guidelines are effective, and because there was little evidence available to show whether continuing concerns about industry publication practices were justified, we sought to generate 'real world' evidence about current practices in the medical publications profession.

We therefore carried out a large-scale, international survey (the Global Publication Survey) to obtain information about the ways in which medical writers and other publication professionals work and, in particular, their awareness of current publication guidelines. We also sought to learn about the processes adopted by pharmaceutical and communications companies to encourage responsible practices and to implement published guidelines. The aim of this survey was to identify areas in which guidelines were understood and enforced, areas for improvement and targets for education and training.

\section{METHODS}

The survey questionnaire was developed by an international team including professional writers and publication managers with experience of working in pharmaceutical and communications companies and in a freelance capacity. Several team members had been involved in developing publication guidelines (see the author list and Acknowledgements section for details). Question topics were based on results of a previous survey of members of the International Society for Medical Publication Professionals (ISMPP). Question and answer options were discussed, drafted and refined by the team. Question types included multiple choice (check one/check all), matrix table, rating (1-5 scale), ranking (top 3), dropdown selection and free text. Logical checks limited the number of questions respondents saw based on 'skip logic' (ie, some questions only appeared if the respondent answered 'yes' to an earlier question). 'Not applicable', 'Don't know' and 'Other (specify)' responses were offered to capture the full range of possible responses.

The questionnaire was transcribed to an online data capture tool hosted by Qualtrics (http://www.qualtrics. com) survey technology. Pilot testing for question content, flow and logic was performed by team members, and the survey was revised as necessary.

Respondents saw a different selection of questions depending on their work sector (categorised as: pharmaceutical or medical device company, agency, contract research organisation (CRO), freelance, journal editor, publisher or academic) and their previous answers. A response was required for each question before the next screen was displayed but users had the option to revisit previously completed questions. Optional questions were included at the end of the core survey allowing participants to offer additional comments.

The survey was announced on 28 November 2012 via email to all members of ISMPP $(n=1105)$. A link included in the email provided individual access to the survey (so each recipient could respond only once and reminders could be sent to non-responders). ISMPP members were also encouraged to share an unrestricted link to the survey with individual colleagues or via their company intranet. The survey was also promoted via social media (LinkedIn and Twitter). Several organisations and companies (including the American Medical Writers Association, the European Medical Writers Association, the European Association of Science Editors, the Committee on Publication Ethics, McCann Complete Medical and Excerpta Medica) publicised the survey to their members or on their websites through December 2012. The survey closed on 18 February 2012.

Respondents could complete the survey anonymously but, to encourage participation, had the option of supplying an email address to enter a draw for one of two iPad tablet computers. Participants were informed that their personal information would not be shared beyond those administering the survey. Respondent-level data were available only to TGaS Advisors (the company responsible for all aspects of survey administration and data aggregation), and were not shared with the survey organisers or sponsors. Descriptive statistics using frequencies and percentages were used. Funding for the incentive prizes was provided by ISMPP. The team members who developed the questionnaire and executed the survey, interpreted the data and developed this publication, worked in their own time or during work time with permission from their various employers but without specific funding or payment.

Research Ethics Committee (Internal Review Board) approval was not required for this survey, as it did not relate to personal medical information, did not involve patients or healthcare professionals (other than in their role as journal editors), was not carried out by an academic institution and participation was entirely 
voluntary. Participants were given the option of supplying an email address if they wanted to enter a prize draw, but could remain completely anonymous if they preferred. We considered that provision of an email address does not necessarily identify an individual (since email addresses do not necessarily indicate name or workplace) and participants were assured that only two people would be contacted to supply the incentive prize. Email details were stored securely by TGaS Advisors and were not revealed to anybody else involved with the survey. Following the guidelines of University College London (although this study was entirely independent of any academic institution) and of the National Research Ethics Service of the UK, such a questionnaire is exempt from requiring Research Ethics Committee approval.

\section{RESULTS}

\section{Respondents}

The survey reached the intended international target audience with responses from 23 countries. The largest responses came from the USA (44\%) and the UK $(39 \%)$. Of the 490 who opened the survey invitation, 469 confirmed that they were involved in publishing industry-sponsored research in peer-reviewed medical journals and completed the survey (table 1). Most respondents $(92 \%)$ worked in pharmaceutical or medical device companies (termed 'industry' respondents; $31 \%$ ), medical communications agencies (termed 'agency' respondents; 51\%) or CROs (3\%) providing publication services to drug and device manufacturers,

\begin{tabular}{|c|c|c|}
\hline Characteristic & $\mathbf{N}$ & Percentage \\
\hline \multicolumn{3}{|l|}{ Workplace } \\
\hline Industry* & 144 & 31 \\
\hline Agency & 238 & 51 \\
\hline $\mathrm{CRO}$ & 15 & 3 \\
\hline Freelance & 34 & 7 \\
\hline Other & 38 & 8 \\
\hline \multicolumn{3}{|c|}{$\begin{array}{l}\text { Experience of working with peer-reviewed publications } \\
\text { (years) }\end{array}$} \\
\hline$<2$ & 36 & 8 \\
\hline $2-4$ & 66 & 14 \\
\hline $5-9$ & 111 & 24 \\
\hline 10 or more & 256 & 55 \\
\hline \multicolumn{3}{|l|}{ Qualification $\ddagger$} \\
\hline Master's degree & 111 & 24 \\
\hline Doctorate & 263 & 56 \\
\hline MD/medical qualification & 26 & 6 \\
\hline Other & 26 & 6 \\
\hline CMPP & 161 & 34 \\
\hline \multicolumn{3}{|c|}{$\begin{array}{l}\text { *Pharmaceutical, biotech or medical device company. } \\
\text { †Communications company. } \\
\text { †Respondents were asked to tick all that applied. } \\
\text { CMPP, Certified Medical Publication Professional; CRO, contract } \\
\text { research organisation. }\end{array}$} \\
\hline
\end{tabular}

or as freelancers $(7 \%)$. The survey was also completed by 5 journal editors, 17 publishers, 9 academics and 7 people working in other roles-results from these categories (total $=8 \%$ ) are not reported in the text due to the low response rate and small numbers but may be viewed at http://www.ismpp.org/gps-raw-data. Owing to the responsive design, the numbers answering each question varied but respondents generally answered about 40 questions. Most respondents took 20-30 min to complete the survey. The full data tables are available at http://www.ismpp.org/gps-raw-data.

Owing to the methods used to promote the survey (including websites and social media), it was not possible to calculate a precise response rate or assess differences between respondents and non-respondents. However, the membership of ISMPP at the time of the survey was 1105 and the response rate from ISMPP members was $20 \%$ (ie, 221 of the respondents responded via the individual links sent out to ISMPP members).

Most respondents were highly educated $(56 \%$ had a doctorate) and experienced $(79 \%$ had worked with medical publications for at least 5 years; table 1 ). Half of the respondents worked in departments that had been involved with over 30 manuscripts in the last year.

\section{Awareness of guidelines}

Almost all industry and agency respondents reported being aware of international guidelines on responsible publication practices (figure 1). Overall, $91 \%$ stated that they routinely referred to Good Publication Practice (GPP2) and 93\% to the International Committee of Medical Journal Editors' Uniform Requirements for guidance on ethical practice. Other sources of guidance consulted routinely by respondents in all sectors included ISMPP $(71 \%)$, medical writers associations (eg, AMWA and EMWA: 39\%) and the Committee on Publication Ethics (COPE: 34\%).

\section{Training}

Regular training on ethical publication practices was compulsory for most respondents in industry and agencies. Mandatory training for employees was reported by $78 \%$ of industry, $79 \%$ of agency and $93 \%$ of CRO respondents. In addition, $68 \%$ of agency respondents reported that their industry customers provided mandatory training for agency personnel. Training at least once a year was reported by $70 \%, 68 \%$ and $71 \%$ for industry, agency and CRO respondents, respectively. Just over half the industry respondents $(55 \%)$ reported that their companies provided training for agency staff or freelancers but only $17 \%$ of agency and $20 \%$ of CRO respondents reported that their organisation provided training for freelancers (while $43 \%$ and $53 \%$, respectively, did not know if freelancers were trained). Similarly, $24 \%$ of the freelancers $(5 / 21)$ reported that they received mandatory training from industry or agency customers. 


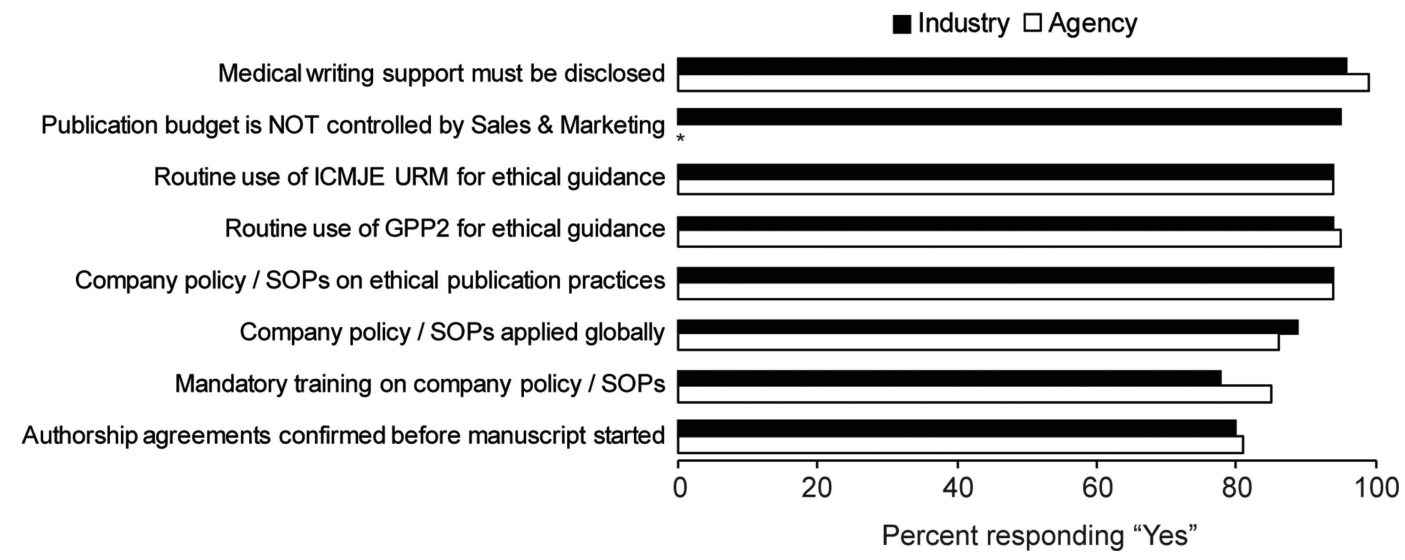

Figure 1 Percentage of survey respondents from industry and agency groups responding 'yes' to selected questions.

Respondents kept up-to-date on current guidelines primarily via training provided by their organisation (64\%), from professional associations $(68 \%)$ and monitoring the literature $(70 \%)$.

\section{Company codes of conduct and publication policies}

In addition to their awareness of external guidelines on ethical publication practices (eg, GPP2), most respondents reported being aware of internal guidelines governing publication practices. Overall, $78 \%$ of respondents worked in an organisation that had a code of conduct governing ethical publication practices. Nearly all the industry $(94 \%)$ and agency $(94 \%)$ respondents, and all the CRO respondents (15/15) stated that their company had guidelines or a policy on ethical publication practices ( 5 industry and 8 agency respondents stated their company did not have such a policy while 3 and 7 , respectively, did not know; figure 1).

Most company guidelines and policies are not publicly available: only $38 \%$ of industry, $35 \%$ of agency and $33 \%$ of CRO respondents reported that these documents were publicly accessible (eg, posted online; figure 2 ).

Of the industry respondents, $67 \%$ stated that their company was committed to peer-reviewed publication of results of all studies in humans. Exceptions to this commitment were studies for which companies did not have control (eg, investigator-initiated studies; reported by 21) and phase 1 studies (ie, early-phase drug development; reported by 14).

Public disclosure of trial results was reported, by those working within the industry, to be fulfilled by: posting results on a public register (92\%), publishing in a peerreviewed journal $(73 \%)$, publishing a conference abstract $(51 \%)$, posting results on a company website (28\%) or a combination of these. When asked about the timing of journal publications, most industry respondents reported that their company policy was to submit a manuscript within 12 or 18 months of study completion (last subject, last visit; $43 \%$ and $18 \%$, respectively). Nevertheless, $24 \%$ of industry respondents reported that their company did not have a target deadline for submitting a manuscript after trial completion (figure 2).

Similar proportions of industry and agency respondents $(80 \%$ and $81 \%$, respectively) reported that authorship obligations were set out in formal agreements before manuscript development (figure 1). Almost all industry $(96 \%)$ and agency $(99 \%)$ respondents, and $100 \%$ of CRO respondents, reported that their

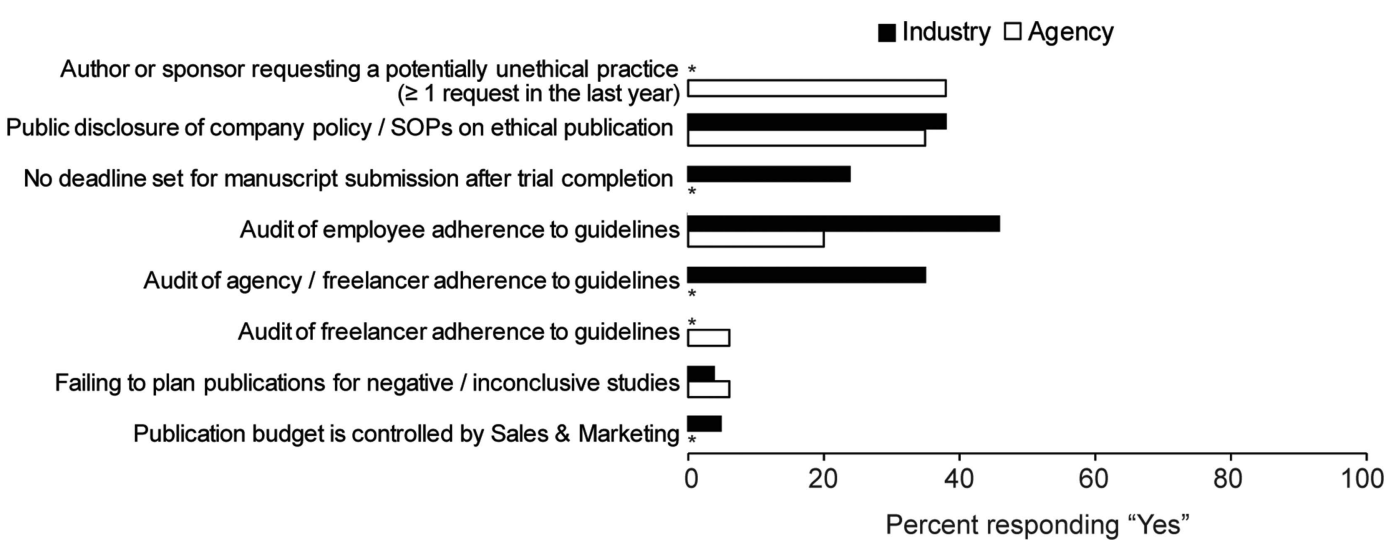

Figure 2 Percentage of survey respondents from industry and agency groups responding 'yes' to selected questions (asterisks indicate that question was only relevant to one group). 
department ensured that authors acknowledge professional medical writing support in every publication (figure 1). Only one respondent from each of the industry and agency groups answered no to this question. However, $11 \%$ of respondents from industry and agency, and $13 \%$ from CROs, were aware of academic authors initially refusing to acknowledge professional writing support in the past 12 months.

\section{Compliance with codes}

Respondents from industry, and to a lesser extent from agencies, reported that their publication practices were subjected to compliance checks. Of the industry respondents, $61 \%$ stated that their company had a formal process for monitoring adherence to company standards and 66 of these ( $46 \%$ of the total) carried out publication audits. A very similar response was obtained from those working in CROs (60\% and $47 \%$, respectively). However, of the agency respondents, $44 \%$ reported that their company had formal compliance monitoring for internal standards and only $20 \%$ carried out publication audits. In addition, about half the industry respondents $(47 \%)$ reported that their company had a formal process for monitoring third-party providers' adherence with company standards and $75 \%$ of these reported that this involved an audit. Agency and CRO respondents stated that some $(43 \%, 47 \%$, respectively), most $(19 \%$, $0 \%)$ or none $(6 \%, 13 \%)$ of their customers had formal, regular processes such as knowledge tests or audits for monitoring suppliers' adherence to the customer's standards, while $27 \%$ of agency and $40 \%$ of CRO respondents did not know if their customers did this. Agency and CRO respondents also reported that their customers used publication management tools to assess compliance (only $6 \%$ and $13 \%$, respectively reported that no customers did this).

Of the industry respondents, 52\% worked in a company operating under a US Government 'Corporate Integrity Agreement' (CIA: see https://oig.hhs.gov/ compliance/corporate-integrity-agreements/index.asp), which typically requires formal compliance checking.

\section{Organisation of publication activities}

Publication activities were primarily governed by medical departments; publications were rarely funded or approved by commercial departments (figure 1). According to the industry respondents, the budget for peer-reviewed publications was usually held by the medical affairs $(72 \%)$ or clinical development $(24 \%)$ departments. Nevertheless, seven respondents $(5 \%)$ stated that the publications budget was held by a commercial department (eg, sales or marketing; figure 2). Involvement of members of commercial departments in developing publications varied, with industry respondents stating that they were: not involved (27\%), provided with information only $(48 \%)$, members of the publication team $(44 \%)$, allowed to suggest target journals for author consideration (22\%), involved in reviewing manuscripts for accuracy (19\%) or part of a formal approval process $(5 \%)$.

\section{Agency response to requests for perceived unethical practices}

Respondents were often, but not always, successful in preventing publication practices they considered unethical. Of the agency respondents, $38 \%$ were aware, in the past 12 months, of their company being asked by an author or a sponsor to do something that they believed contravened ethical practices $(10 \%$ once and $28 \%$ more than once) while $2 / 15$ CRO respondents (13\%) reported such requests. Respondents reported that their agency's response was to explain the need for compliance, resulting in the request being withdrawn or amended (92\% and both CRO cases), or to refuse to accept the work (1\%); however, 3\% (3/90) stated that the agency ultimately complied with the request.

Although a slightly higher proportion of freelancers $(17 / 34,50 \%)$ reported requests which they believed constituted unethical practices, this should not be overinterpreted due to the small group size; $12 \%(2 / 17)$ of freelancers accepted such work.

\section{Information provided to authors}

Authors were routinely provided with various documents and data sources to facilitate manuscript preparation. These documents included (for agency and industry respondents respectively): clinical study report $(81 \%$, $79 \%)$, study protocol $(79 \%, 83 \%)$, summarised data $(67 \%, 66 \%)$, statistical report $(58 \%, 62 \%)$, manuscript outline $(58 \%, 56 \%)$, statistical analysis plan $(42 \%, 54 \%)$ and raw data/data tables $(42 \%, 42 \%)$.

\section{Enforcement of authorship criteria}

Respondents actively enforced compliance with authorship criteria (table 2).

Of the industry respondents, $33 \%$ were aware of an author being removed from a manuscript within the past 12 months and $94 \%$ stated that this was due to the individual not meeting authorship criteria. Other reasons for recommending removal of an author included individuals leaving the company (28\%) or not agreeing to adhere to ethical publication practices (13\%; respondents could select more than 1 reason). Three respondents from industry and two from agencies reported authors being removed because they disagreed with the interpretation of the data. Eight freelancers reported recommending the removal of an author, in all cases because the individual did not meet authorship criteria.

\section{Publishing negative findings}

Most industry respondents' companies attempted to publish negative or inconclusive results. Of the industry respondents, $63 \%$ reported that their department had supported the publication of a study with negative or inconclusive results $(17 \%$ stated that this had not 
Table 2 Responses to the question 'In the past 12 months, to your knowledge, how often has your department recommended to the lead author the removal of a coauthor from a manuscript or abstract that was in development?'

\begin{tabular}{llllll}
\hline & Never & Once & More than once & Other & Do not know \\
\hline Industry $(n=144)$ & $44 \%(64)$ & $10 \%(15)$ & $22 \%(32)$ & $2 \%(3)$ & $21 \%(30)$ \\
Agency $(n=238)$ & $24 \%(58)$ & $11 \%(26)$ & $35 \%(84)$ & $3 \%(6)$ & $27 \%(64)$ \\
CRO $(n=15)$ & $27 \%(4)$ & $33 \%(5)$ & $7 \%(1)$ & $7 \%(1)$ & $27 \%(4)$ \\
Freelance $(n=34)$ & $74 \%(25)$ & $9 \%(3)$ & $15 \%(5)$ & $3 \%(1)$ & 0 \\
\hline CRO, contract research organisation.
\end{tabular}

happened and $19 \%$ did not know). Only six respondents $(4 \%)$ were aware of a negative or inconclusive study for which publication was not planned, in three cases this was due to the discontinuation of product development. Reponses were similar in the agency (and CRO) groups, with $58 \%(60 \%)$ aware of the publication of negative findings and 6\% (13\%) being aware of negative findings for which publication was not planned. Of the freelancers, $38 \%$ had been involved with the publication of negative findings in the past 12 months.

\section{Freelance responses}

Only 34 freelance publication professionals responded to the survey and some of these did not answer all questions, therefore the results may not be representative and should not be overinterpreted. However, the following findings were noteworthy: 12/34 (35\%) did not know whether their customers had publication guidelines; $15 / 21(71 \%)$ stated that they did not receive mandatory training and $21 / 34(62 \%)$ stated that their clients did not have formal, regular processes to monitor their adherence to standards. However, freelancers reported routinely consulting published guidelines $(100 \%$ for ICMJE, 91\% for GPP2) on ethical issues.

\section{DISCUSSION}

This is one of the largest international surveys designed to capture information about current knowledge and implementation of publication guidelines within the pharmaceutical, medical device and medical communications industries. Our survey showed high reported levels of knowledge of the various publication guidelines among publication professionals, with over $90 \%$ of respondents stating that they routinely referred to them. Although these published guidelines (such as GPP2) are not generally enforced by legislation, according to our survey most companies have codes of conduct, policies or internal guidelines that reflect and enforce them. Similarly, most companies (industry and agencies) provide mandatory training to internal staff, while many pharmaceutical and medical device companies also train agency personnel who develop publications on their behalf. The relatively low rates of training and auditing of freelancers suggested in this survey (albeit from a small number of respondents), however, may represent a problem that companies, agencies and authors who work with freelancers should address.
Many pharmaceutical companies in the USA currently operate under CIAs. For such companies, many aspects of voluntary good publication practice guidelines are legally enforced. An analysis of 12 such agreements issued from 2009 to mid-2012 showed that they included requirements for author agreements, publication plans and the posting of study results. ${ }^{15}$ The CIA requirements were consistent with GPP and the ICMJE guidelines and also mandated training and reporting. CIA requirements apply to the pharmaceutical companies and to their management of any third-party suppliers, therefore, they will also affect many agencies, freelancers and CROs. Similarly, even companies without a CIA often require suppliers to follow their policies. Therefore, for many agencies and freelancers, failure to follow a customer's policy could mean loss of future business, thus the underlying guidelines are viewed as compulsory rather than optional.

The importance with which guidelines are viewed is reflected in the effort (and therefore, time and money) companies invest in monitoring compliance. Our survey found that many pharmaceutical and device companies have formal monitoring processes including publication audits. Since our survey may have included several respondents from the same company, the results cannot indicate precisely what proportion of companies have such processes but it is probably well over half. The fact that fewer agencies appear to audit to their own internal standards is not surprising, since many reported being regularly audited by their customers. However, rates of training and auditing of freelancers (by pharmaceutical companies and agencies) are less reassuring and suggest room for improvement.

Many companies use specialist publication planning software (such as Datavision or PubSTRAT). Our survey shows that such tools are used for publication project management and to monitor and demonstrate compliance with company procedures, for example, by ensuring that all authors have approved a manuscript outline, drafts and the final version.

Lack of transparency surrounding company involvement, non-disclosure of competing interests and misleading authorship have been causes for concern in industry-sponsored publications in the past. ${ }^{16}$ In particular, the occurrence of 'ghost-writing' (ie, unacknowledged use of medical writers) and guest or honorary authorship (ie, named authors not fulfilling journal authorship criteria) were spurs for the development of 
general and specific guidelines. ${ }^{3} 411{ }^{17}$ It is therefore encouraging that $96-100 \%$ of respondents (working in pharmaceutical and medical device companies, agencies and CROs) stated that their department ensured that medical writers were acknowledged (thus preventing the medical writers from being 'ghost writers'). Of concern, however, is the fact that some academic authors apparently continue to be reluctant to acknowledge writing support. Although publication professionals can alert authors about the need for disclosure, academic institutions clearly have an educational role to play.

The ICMJE authorship criteria (which are widely endorsed by medical journals and which were revised after the survey) state that listed authors should have made substantial contributions to the research and its publication. Therefore authorship cannot be determined until a publication is developed. Individuals involved with the research being reported may be invited to become authors, but will not qualify unless they also take an active role in the publication. It is therefore encouraging that our survey found that industry sponsors of research and publication agencies and freelancers working for them, actively enforce authorship criteria by suggesting that individuals should be removed from author listings if they fail to meet the ICMJE or other agreed criteria (see table 2). It can take considerable courage for a freelancer or agency employee to suggest that a proposed author has not contributed sufficiently to merit being listed, especially if that person is a senior academic or well-known expert. Being the one to identify a guest author carries the risk of damaging relationships and possibly work prospects. However, arguably there is an even greater and more serious risk of damaged relations, reputations and work prospects if a publication professional fails to raise authorship concerns which are later raised by a journal. Early clarification of authorship obligations should reduce the risk of guest authorship and it was encouraging that most respondents reported that authorship agreements were confirmed before manuscript preparation started.

As we cannot tell how often proposed authors fail to contribute to publications, our survey cannot show how often this is overlooked, but the fact that almost one-third of industry respondents were aware of instances of authors being removed because they did not meet authorship criteria suggests that guidelines are being enforced. However, this question also revealed that three industry $(2 \%)$ and two agency $(0.8 \%)$ respondents were aware of authors being removed from publications because they disagreed with the interpretation of the findings. We cannot tell how many cases these represent, since several respondents may have reported the same case, nor can we tell whether the disagreements about interpretation were with the sponsor (which would be concerning) or between coauthors, but this issue needs further scrutiny.
The difficulties of interpreting the ICMJE authorship criteria in some situations have been examined in a study coordinated by the Medical Publishing Insights and Practices (MPIP) initiative. ${ }^{18}$ Using vignettes presenting 'challenging real-world authorship scenarios' this study found that journal editors, clinical investigators, medical writers and publication planners had different views about who qualified for authorship and suggested that additional guidance might be helpful.

\section{Limitations}

We had originally hoped to compare or confirm responses from publication professionals with those from journal editors and academic investigators, however, we were less successful in promoting the survey among these groups than among publication professionals and consider the response from these sectors too small to be reliable. The number of responses from freelance publication professionals was also disappointing and it is therefore important not to overinterpret the findings from this group. Care should also be taken in extrapolating proportions of respondents to proportions of companies or agencies, since we had no way of measuring the numbers of respondents per company.

We also recognise that our survey, like many others, carried the risk of self-selection bias. Our survey was promoted mainly via professional organisations such as ISMPP and AMWA/EMWA which promote ethical publication practices. Those choosing to respond to a survey supported by these associations may be more likely to follow and report ethical publication practices. Also, those who chose to complete the survey may have had a special interest in, or concerns about, the issues covered. Our respondents therefore may not be representative of all publication professionals and may be better informed about the topics covered by this survey and more aware of guidelines (eg, from attending professional meetings or taking part in educational activities). However, due to the methods used to publicise the survey (including websites and social media rather than to a clearly defined population) it was not possible to compare characteristics of respondents and non-respondents. We also acknowledge that our respondents came primarily from higher-income countries. Our findings may not be applicable to publication practices in lower income countries, particularly given the significant influence of country income on publication practices. ${ }^{5} 19$

Another problem with any survey is if respondents give 'socially desirable' rather than truthful answers. One reason we have confidence in our findings is that responses were not uniform, for example, only $34 \%$ reported referring to the COPE guidelines compared with $91 \%$ for the ICMJE guidelines. The fact that the survey highlighted weaknesses as well as strengths (eg, the proportion of freelancers who receive training) also suggests that responses were factual. 


\section{Comparison with other surveys}

Journal editors' awareness of various guidelines was measured in 2007 in an international survey to which 111 editors of biomedical journals responded. ${ }^{20}$ This survey noted that 'awareness and use of guidelines and other resources on publication ethics was generally low'. Over half the editors $(55 \%)$ reported being unaware of the ICMJE Uniform Requirements and two-thirds (67\%) were unaware of the GPP2 guidelines, while the proportion of editors reporting that they had used these guidelines were just $24 \%$ and $9 \%$, respectively. This represents a marked contrast to the publication professionals responding to our survey, over $90 \%$ of whom reported that they routinely referred to these two guidelines.

Another survey of 183 editors of high-impact medical journals in 2009 found that, although $76 \%$ had received training in medical editing, they performed poorly when answering questions about: authorship (only 30\% gave 'correct' answers, ie, consistent with commonly cited guidelines), plagiarism (17\% correct), peer review $(16 \%$ correct) and conflicts of interest $\left(15 \%\right.$ correct).$^{21}$

A 2012 survey of 294 healthcare professionals found that $42 \%$ were unaware of the GPP guidelines. ${ }^{22}$ This survey also found that the doctors $(69 \%$ of whom were authors on peer-reviewed articles) were unfamiliar with, or disagreed with, the ICMJE authorship criteria, since a considerable proportion considered that data collection $(51 \%)$ or general supervision of a laboratory $(33 \%)$ alone were criteria for authorship. Nevertheless, $66 \%$ of respondents in the healthcare practitioners' survey stated that they would be concerned about 'the involvement of pharmaceutical employees as authors or reviewers of a draft manuscript'. A smaller survey of surgeons in Croatia (in 2011) found that only 54\% (31/57) were aware of the ICMJE guidelines although 74\% (43/ 58 ) of the respondents had worked on at least two manuscripts for publication in the past 2 years. ${ }^{23}$

A large scale, repeated survey of medical writers (who were nearly all members of AMWA or EMWA), ${ }^{24}$ which attracted 746 responses in 2005, and 662 in 2008, found lower levels of familiarity with guidelines than the current survey (carried out in 2012) but showed that awareness had risen between 2005 and 2008. For example, the proportion of respondents claiming to be familiar with ICMJE guidelines rose from 54\% in 2005 to $75 \%$ in 2008. The figures for GPP were $43 \%$ and $58 \%$, and for the EMWA guidelines (published in 2005) $27 \%$ and $46 \%$, respectively, in 2005 and 2008. The AMWA/EMWA survey also asked writers about their experience of being involved with unacknowledged writing work (ie, ghostwriting). In 2005, 39\% stated that this practice had decreased in the past 5 years $(52 \%$ stated that it was unchanged and $8 \%$ that it had increased). In 2008, 63\% considered that ghostwriting had decreased, $30 \%$ stated that it was unchanged and $6 \%$ that it had increased in the past 5 years. The proportion of professional writers reporting that they always requested acknowledgement for a substantial contribution to a manuscript also rose from $25 \%$ in 2005 to $43 \%$ in 2008. The survey was repeated in 2011 (with 620 respondents) ${ }^{25}$ and responses showed a clear decrease in the proportion of manuscripts (not necessarily all for peer-reviewed journals) with undisclosed contributions (ie, ghostwriting) which fell from $62 \%$ in 2005, to $42 \%$ in 2008 and $33 \%$ in 2011.

Ghostwriting of review articles commissioned by pharmaceutical companies was a particular concern when the first GPP guidelines were developed. ${ }^{26} \mathrm{~A}$ survey of authors published in six, high-impact general medical journals found a decline in ghost authorship between 1996 and 2008, and a significant decrease (from $26 \%$ to $15 \%$ ) in honorary authorship (which often accompanies ghostwriting) for review articles and editorials (although not for other types of articles). ${ }^{27}$

Our survey did not get sufficient response from academics to draw any conclusions about their understanding of their role as authors of medical publications. We hope that the full report of the MPIP authorship project will cast more light on this. ${ }^{18}$

\section{RECOMIMENDATIONS}

While many of our findings are heartening (figure 1), some indicate a need for further action (figure 2). We hope that the professional organisations who were involved with this survey (in particular, ISMPP, AMWA and EMWA) along with pharmaceutical and medical device companies, will use the findings to identify topics for future training or discussion. We suggest they might focus on the following areas:

- Although many companies and agencies had publication policies, it is disappointing that so few of these policies were made public. We encourage companies to post their publication policies on their websites. Companies might also consider publishing the results of publication audits to indicate how closely they comply with guidelines (eg, what proportion of clinical trials are published) and to help identify obstacles to compliance.

- While our survey suggests that most pharmaceutical companies and agencies have a code of conduct and provide mandatory training on responsible publication practices to relevant staff, this is not always the case, and there is room for improvement, especially for those that subcontract work to freelancers. We therefore recommend that companies, agencies and professional groups (such as ISMPP, EMWA and AMWA) put renewed effort into ensuring that all publication professionals receive effective training. Freelancers should be accountable for their own training, or ensure they receive sufficient training from their customers. We also recommend that individuals involved less directly in publications should be made aware of the relevant guidelines.

- Although pharmaceutical companies generally provide invited authors with study reports and 
protocols, this was not universal. Named authors should always have access to study results to ensure they can understand and interpret the findings.

- The reported requests from authors or companies for agency staff to do something that the publication professionals considered unethical warrants further investigation. Our survey did not ask about reporting mechanisms for perceived unethical practices, or how strongly these are communicated and used. We encourage agencies to develop systems for handling such situations. Further education of authors and industry staff, particularly those who are not familiar with the stringency of current guidelines, should help reduce such requests.

- The number of freelancers responding to the survey was small $(<50)$, but some of their responses suggested differences from publication professionals working in companies. We therefore hope a similar survey might be undertaken focusing on the needs of this community and their publication practices to better understand areas where they may need support.

These suggested actions focus primarily on pharmaceutical companies and communications agencies. However, clinical trials and their publication involves many players, and other surveys suggest that healthcare professionals (investigators and academics) and journal editors would benefit from greater knowledge of published guidelines and may, in fact, be less familiar with such guidelines than publication professionals. Given the financial and human resources required to ensure timely, accurate and complete reporting of research results, ${ }^{28}$ it is likely that the demand for, and use of, publication professionals will increase. Our survey findings indicate that further involvement of knowledgeable and experienced medical publication professionals, who are familiar with guidelines on reporting clinical trials and publication ethics, should be viewed as a positive step in achieving timely and reliable reporting. Our survey findings also complement evidence which shows that manuscripts prepared with professional writing or editing support are more likely to comply with reporting requirements, ${ }^{29}$ less likely to be retracted for misconduct ${ }^{5}$ and are accepted for publication more quickly, ${ }^{30}$ than those prepared without such support.

Authorship of research publications is not straightforward and the ICMJE criteria have recently been revised. Our survey did not examine views on existing criteria or problems with their implementation, although other surveys have done this. ${ }^{31}{ }^{32}$ We are aware of current initiatives aimed at deepening understanding and developing consensus around authorship and the transparency of contributions and we welcome these. We would also welcome surveys that test how well non-industry authors and editors comply with voluntary guidelines issued by their professional associations and how such compliance is checked.

\section{Conclusions}

Despite criticism that most publication guidelines are voluntary, our survey suggests that the major guidelines are widely known and implemented by publication professionals working in pharmaceutical and medical device companies, communication agencies, CROs and as freelancers. Many companies enforce these guidelines through policies, codes of conduct, standard operating procedures and audits. For companies operating under a CIA, many of the GPP2 and ICMJE recommendations are mandated and audited by the Office of the Inspector General via independent auditors. When the GPP2 guidelines were first developed (in the late 1990s), publication audits were unheard of, yet many companies now regularly audit their practices against guidelines such as GPP2 and CIAs mean that many of the GPP2 recommendations are now legally enforced and monitored.

While there is no room for complacency, and we make no claim that all problems with the publication of industry-funded research have disappeared, this survey, taken together with others showing improved acknowledgement of medical writers, and reductions in guest authorship, suggests that guidelines such as GPP (published in 2003) and GPP2 (2010) have had a definite positive effect on publication practices and that most companies and individual publication professionals are striving to do the right thing.

\section{Author affiliations}

${ }^{1}$ Sideview, Princes Risborough, UK

${ }^{2}$ ProScribe Envision Pharma Group, Noosaville, Australia

${ }^{3}$ Faculty of Health Sciences, University of Queensland, Brisbane, Queensland, Australia

${ }^{4}$ Faculty of Science, Health, Education and Engineering, University of the Sunshine Coast, Queensland, Australia

${ }^{5}$ KnowledgePoint360 Group, Macclesfield, Cheshire, UK

${ }^{6} \mathrm{TGaS}$ Advisors, East Norriton, Pennsylvania, USA

${ }^{7}$ AstraZeneca, Alderley Park, Cheshire, UK

${ }^{8}$ Complete Medical Communications, Macclesfield, Cheshire, UK

Acknowledgements The authors thank the organisations and individuals who helped publicise and execute the survey, in particular Mike Smith (Alphabiocom) and Fiona Steinkamp (NovoNordisk). They also thank Dr Serina Stretton (ProScribe Medical Communications) for her assistance with the figures.

Contributors All authors were involved in developing the questionnaire and analysing or interpreting the data. All authors reviewed the manuscript and discussed it critically over several revisions, and agreed to submit it for publication. In addition, EW wrote the first draft of the paper, JF was responsible for data management and analysis and KW presented initial findings at the 2013 ISMPP meeting and prepared the figures.

Funding Funding for the incentive prizes was provided by ISMPP. Data collection and analysis was provided (free of charge) by KnowledgePoint360 via TGaS Advisors.

Competing interests EW is an author of the original Good Publication Practice (GPP) guidelines, the antighostwriting checklist, the EMWA guidelines on the role of medical writers in publications and several COPE guidelines. She works as a freelance publications consultant and has provided training to many pharmaceutical companies and communication agencies and receives fees and expenses for talks and workshops on publication guidelines. KW conducts and publishes research on ethical medical writing practices. She 
is actively involved in not-for-profit associations that advocate ethical publication practices. She is paid to provide ethical medical writing training courses and services for not-for-profit and for-profit clients, particularly in the Asia-Pacific region. AC has served on the ISMPP Certification Board of Trustees. ST is the chair of the ISMPP Advocacy and Outreach Committee. AC, VA, TG and ST are employed by medical communications companies that provide publications services to authors and industry sponsors. JG is on the Board of Trustees of ISMPP and is a steering committee member of the Medical Publications Insights and Practices (MPIP) initiative. JG and TG are/ were employees of AstraZeneca and own shares in the company. JF is an employee of TGaS Advisors, which, at the time of the survey, was a division of the KnowledgePoint360 Group. All authors (except JF) are members of ISMPP.

Provenance and peer review Not commissioned; externally peer reviewed.

Data sharing statement The full questionnaire and raw data aggregated by sector (industry, agency, freelance) are available at http://www.ismpp.org/ gps-raw-data.

Open Access This is an Open Access article distributed in accordance with the Creative Commons Attribution Non Commercial (CC BY-NC 3.0) license, which permits others to distribute, remix, adapt, build upon this work noncommercially, and license their derivative works on different terms, provided the original work is properly cited and the use is non-commercial. See: http:// creativecommons.org/licenses/by-nc/3.0/

\section{REFERENCES}

1. Sismondo S. Ghosts in the machine: publication planning in the medical sciences. Soc Stud Sci 2009;39:171.

2. Fugh-Berman A. The haunting of medical journals: how ghostwriting sold 'HRT'. PLOS ONE 2010;7:e1000335.

3. WAME Policy Statement: ghost writing initiated by commercial companies. http://www\%20wame\%20org/resources/policies\#ghost

4. Jacobs A, Wager E. EMWA guidelines on the role of medical writers in developing peer-reviewed publications. Curr Med Res Opin 2005;21:317-21.

5. Woolley K, Lew R, Stretton S, et al. Lack of involvement of medical writers and the pharmaceutical industry in publications retracted for misconduct: a systematic, controlled, retrospective study. Curr Med Res Opin 2011;27:1175-82.

6. Kaiser K, Cofield S, Fontaine $\mathrm{K}$, et al. Is funding source related to study reporting quality in obesity or nutrition randomized control trials in top-tier medical journals? Int J Obes 2013;36:977-81.

7. Smith SM, Wang AT, Katz NP, et al. Adverse event assessment, analysis, and reporting in recent published analgesic trials: ACTTION systematic review and recommendations. Pain 2013;154:997-1008.

8. Lundh A, Sismondo S, Lexchin J, et al. Industry sponsorship and research outcome. Cochrane Database Syst Rev 2012;12: MR000033.

9. Als-Nielsen B, Chen W, Gluud C, et al. Association of funding and conclusions in randomized drug trials: a reflection of treatment effect or adverse events? JAMA 2003;290:981-8.

10. Wager E, Field EA, Grossman L. Good publication practice for pharmaceutical companies. Curr Med Res Opin 2003;19:149-54.

11. Graf C, Battisti WP, Bridges D, et al. Good publication practice for communicating company sponsored medical research: the GPP2 guidelines. BMJ 2010;339:b4330.
12. Norris R, Bowman A, Fagan JM, et al. International Society for Medical Publication Professionals (ISMPP) position statement: the role of the professional medical writer. Curr Med Res Opin 2007:23:1837-40.

13. AMWA Code of Ethics. http://www\%20amwa\%20org/amwa_ethics http://www.amwa.org/amwa ethics

14. Goldacre B. Bad pharma. London: Fourth Estate, 2012.

15. Rodino FJ. Corporate integrity agreements. What they say about publications, publication planning, transparency, and ICMJE. Ther Innov Regul Sci 2013;47:50-6.

16. Laine C, Mulrow CD. Exorcising ghosts and unwelcome guests. Ann Intern Med 2005:143:611-12.

17. Gøtzsche PC, Kassirer JP, Woolley KL, et al. What should be done to tackle ghostwriting in the medical literature? PLoS Med 2009;6: e1000023.

18. Marusic A, Hren D, Bhattacharya A, et al. Deciding authorship: survey findings from clinical investigators, journal editors, publication planners, and medical writers. Chicago: 7th International Congress on Peer Review and Biomedical Publication, 2013. 8-9-2013.

19. Stretton S, Bramich NJ, Keys J, et al. Publication misconduct and plagiarism retractions: a systematic, retrospective study. Curr Med Res Opin 2012;28:1575-83.

20. Wager E, Fiack S, Graf C, et al. Science journal editors' views on publication ethics: results of an international survey. $J$ Med Ethics 2009;35:348-53.

21. Wong V, Callaham ML. Medical journal editors lacked familiarity with scientific publication issues despite training and regular exposure. $J$ Clin Epidemiol 2012;65:247-52.

22. Good Publication Practice: the awareness and views of healthcare professionals. http://www epghealthmedia com/industry-reports/ HCP-views-on-GPP/

23. De Faoite D, Bakota B, Staresinic M, et al. Awareness, attitudes, and perceptions of Croatian-based orthopedic and trauma surgeons toward scientific manuscripts, publishing internationally and medical writing. Results of an online questionnaire. Coll Antropol 2013;1:165-8.

24. Jacobs A, Hamilton CW. Decreased evidence of ghostwriting in a 2008 vs 2005 survey of medical writers. Write Stuff 2009;18:118-23.

25. Hamilton CW, Jacobs A. Evidence of decreased ghostwriting in a series of three surveys of medical communicators conducted between 2005 and 2011. AMWA J 2012;27:115.

26. Wager E. Publication ethics: the shift from philosophy to compliance. Regul Aff J 2011:(2nd Feb)18-19.

27. Wislar JS, Flanagin A, Fontanarosa PB, et al. Honorary and ghost authorship in high impact biomedical journals: a cross sectional survey. BMJ 2011;343:d6128.

28. Woolley KL, Gertel A, Hamilton C, et al. Poor compliance with reporting research results-we know it's a problem ... how do we fix it? Curr Med Res Opin 2012;28:1857-60.

29. Jacobs A. Adherence to the CONSORT guideline in papers written by professional medical writers. Write Stuff 2010;19: 196-200.

30. Bailey M. Science editing and its effect on manuscript acceptance time. AMWA J 2011;26:147-52.

31. Pignatelli $\mathrm{B}$, Maisonneuve $\mathrm{H}$, Chapuis $\mathrm{F}$. Authorship ignorance: views of researchers in French clinical settings. J Med Ethics 2005;31:578-81.

32. Bhopal R, Rankin J, McColl E, et al. The vexed question of authorship: views of researchers in a British medical faculty. BMJ 1997;314:1009-12. 